\title{
BUILDING A QUALITY COST MODEL FOR ADDITIVE MANUFACTURING
}

\author{
Musab Hajalfadul \\ Faculty of Engineering, University of Khartoum, \\ Khartoum, Sudan \\ Martin Baumers \\ Faculty of Engineering, The University of Nottingham, \\ Nottingham, United Kingdom
}

\begin{abstract}
Additive manufacturing (AM) is the technology used to manufacture products directly by layering the material, so no special tools are needed to produce the parts. AM is favoured by the producers since it is costeffective when it is used for small production volumes, leading to ease in the customization of products. Previous attempts had been made to develop a cost model for AM. However, most of these attempts did not consider the quality cost. The model developed by Schmid and Levy was the first cost model focusing on the quality cost of AM, they found that quality cost of AM may reach up to $16 \%$ of total manufacturing cost. The current research made a further investigation on quality cost. As a result, a detailed cost model for all AM technologies was made. The developed model considered all quality aspects along the AM process chain. The developed model was then used to calculate the quality cost when building several copies of a part; it was found that quality cost was about $20 \%$ of the total manufacturing cost. The work then focused on investigating the effect of making replacements for defect parts; this investigation revealed that it was better always to make replacements than just dispose of the defects. Finally, the study recommends the study of the exact effect of applying quality control activities on the percentage of defects, so a precise prediction for the quality cost may be attained. Another recommendation is to extend the detailed cost model for all AM technologies, considering the specific variables in each one.
\end{abstract}

Keywords: Additive manufacturing, selective laser sintering, cost model, quality cost

\section{INTRODUCTION}

Additive manufacturing (AM) is the technology of making objects directly from three-dimensional (3D) model, usually layer upon layer, as opposed to subtractive technologies [1]. In the past decades, the traditional manufacturing techniques were used extensively for metals, and other traditional materials. However, it is more challenging to utilize Am to make composite structures due to their complex fibrous nature [27]. However, the central concept of all AM techniques is to use computer aided design (CAD) software to generate a 3D model which is then sent to AM machine [7].

Additive manufacturing can be categories into seven techniques; Vat photopolymerization process, powder bed fusion (PBF), extrusionbased systems, printing process, sheet lamination process, beam deposition process, direct write (DW) technology [8].

Under the branch of PBF, there is a common technology that is used to manufacture metallic parts directly from powder; this technology is called selective laser melting (SLM) or selective laser sintering (SLS). Thin powder layers generated on a metallic base plate [9]. A laser beam with high power is used to scan the slices of the 3D CAD model, so the powder material is densified [10].

Creating products of complex shapes and geometries is considered as one of the essential characteristics of AM. This feature gives AM freedom in design. Some of the published work like the one carried by [11] suggests that the addition of complexity to a design can be carried out at no extra cost with AM.

This essential existence of design flexibility would allow the users of AM to replicate any design they can think of. [11] Also, suggests that this complexity would be beneficial in production economics by decoupling the complexity from the cost of the manufacturing process. This characteristic was also reported upon by [12] , who also explored AM ability to manufacture parts of great customisation. 
The parts in AM are built discretely; each run of the machine is called a "job" or a "build". Each build would have multiple parts, and each part could be intended for entirely different use.

Consider the Eon SLS machine in the AM Lab of the University of Nottingham, the building volume could contain parts sent by different researchers, and each part may be used for a different study (could be of various sizes and geometries), yet they are all built in the same volume $[13,14]$ have emphasised on this ability of $\mathrm{AM}$ and have described AM as a parallel manufacturing technology".

\section{AM cost}

AM cost is usually presented as one of the major hurdles before accepting it in the manufacturing industry. AM costs in the most cases are divided into two categories; direct production cost those are well-structured, and indirect ill-structured costs. For instance, the first group may involve material, labour and energy cost, and the second category contains the other factors such as inventory, transportation, and failures, $[15,16]$. Well-structured costs had the primary Figure 1.

Most cost models had been made for AM were following the activity based cost estimation $(\mathrm{ABC})$. This technique is found under the concentration in traditional cost models who were intended to make a comparison among AM techniques each other or conventional manufacturing methods and were also studying cost optimisation. Recent work has argued taking the whole life cycle costs of AM produced parts in the account to obtain a more efficient cost-benefits analysis $[17,18]$.

Several techniques were used to estimate the cost of products has developed a classification and categorised them into two main groups [19].

The first branch related with the techniques used to compare the new product with an already existing one to find matches, and the similarities between them is used to predict the cost for the new one; those techniques called the qualitative methods for cost estimation.

The second group is quantitative methods; those techniques make a detailed breakdown of required manufacturing processes. More details about the classification are shown in

quantitative techniques, specifically in the analytical methods.

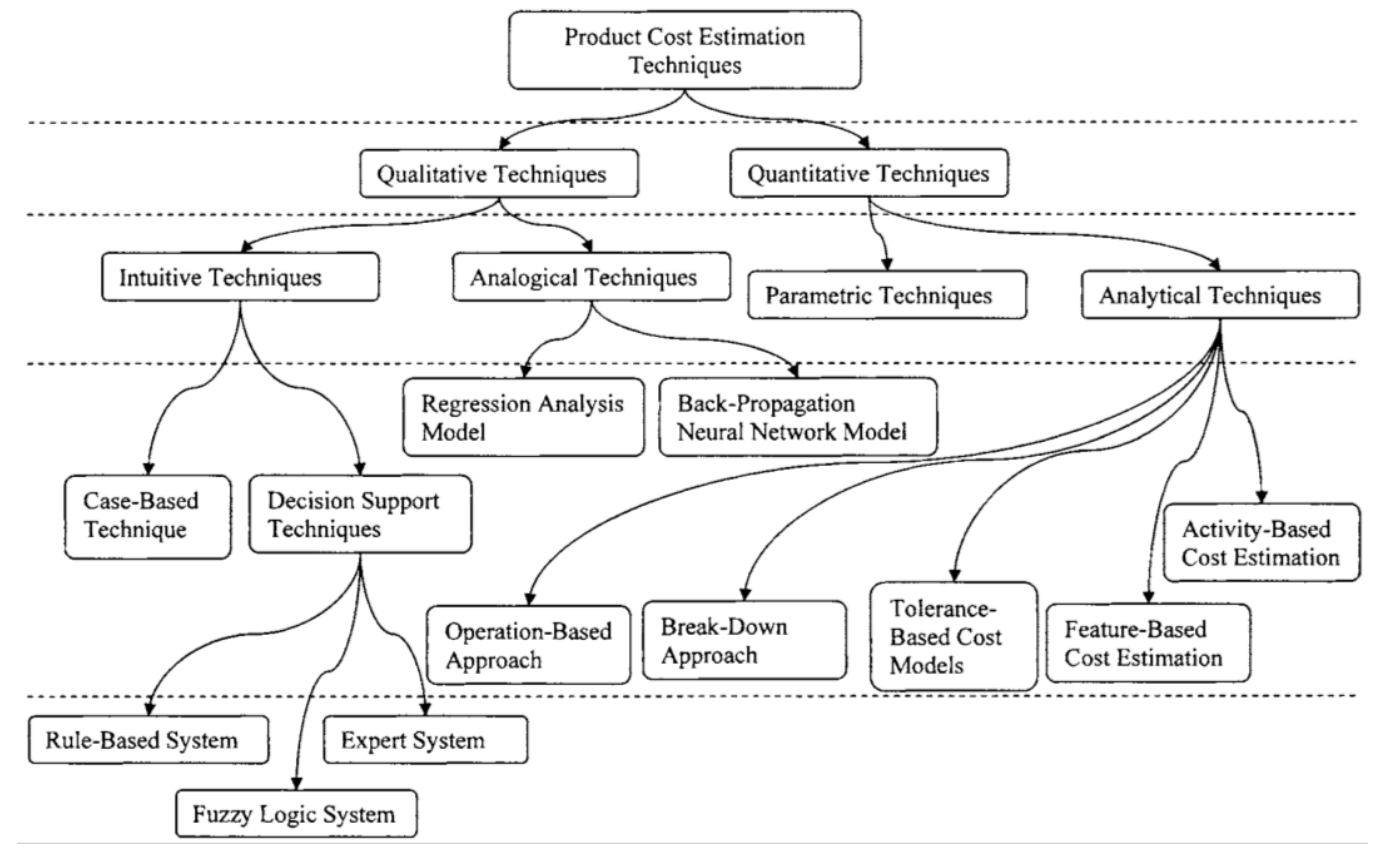

Figure 1: Product Cost Estimation Techniques (Niazi et al., 2005)

Alexander et al. [20] has developed one of the earliest cost models. It was established based on fused deposition modelling (FDM) and stereolithography technologies.
(SLA) 
Also, the model that proposed by Hopkinson and Dicknes [21] was a considerable basic cost model. The authors assume that one type of product will be built in the AM machine in its entire lifetime. They also took into account materials costs, machine costs, and labour costs.

Further work was done on the model by [14]. The new model considers more than one product in a single build. Furthermore, more attention had been paid for indirect costs such as production overhead, part design, and managerial cost, and the cost of reusing powder material and wastes.

An important finding in [13] is that the production volume is considerable factor and cannot be ignored and concludes that a higher and more reasonable cost associated with lower production volumes and the opposite for higher production volumes, as opposed to Hopkinson and Dickens who expected a constant unit cost that does not depend on the production volumes.

Gibson et al. [8] included, even more, costs, for example, he expanded the labour cost by adding cleaning and resetting the machine cost, costs associated with machine operation and material costs.

To date, one of the most comprehensive models was developed in [10]. This model takes account of detailed cost estimations based on the full selective laser melting (SLM) process chain, and it suits, even more, a variety of jobs.

\section{AM quality and quality cost}

Despite the rapid development of AM, it suffers from the absence of a mature quality management system. Both ASTM and ISO recognised this barrier and began to put global standards, even though there are still in basic discussion [22]. However, several attempts were made to define a quality structure for AM processes, and some of them were used in some published works.

To gather, classify, and calculate the quality cost, there are numerous approaches can be used. The first one is the traditional PAF technique proposed by [23] and [24], this method categorises quality cost in prevention, appraisal, and failure costs.

Crosby's model [25] similar categories as PAF model. Crosby defines quality as "conformance to requirements", and subsequently quality cost will be the summation of conformance cost and nonconformance cost [25].

Ross et al. [26] proposed another quality cost model based on the processes, and it was used for the cost of the quality firstly by Marsh et al. [27]; it represents quality cost methods that concentrate on process rather than products or services.
Recent quality cost model was developed in [22]. In that model, the authors have applied cause and effect analysis to find the required actions to assure the product quality. They established a basic procedure, for instance, they considered the calibration and preventive maintenance of the AM machine in order to get consistent quality.

\section{APPROACH}

The approach followed to build the quality cost model started by finding the quality cost drivers in general manufacturing processes then defining those related to $\mathrm{AM}$ in the generic process chain of AM. The process chain of AM consists of seven steps before the product be ready for use [8] among those steps many activities may be inserted to assure the quality of the process and manufactured parts.

Chiadamrong et al. [28] Had defined general quality management for the manufacturing process, and they derived the equations governing the cost of those activities. However, not all elements of those equations were applied to AM technologies. Therefore the only equation suitable for AM were to be selected, some literature such $[22,29]$ were used for picking process.

The final step was to find the formula to calculate the unit cost for parts made through AM. The unit cost had three cases according to failures scenarios, whether there were not any defects in the building process, or some parts failed. The second decision was about making replacements for defects or not.

\section{RESULTS AND ANALYSIS}

The first step in building a quality cost model for AM was to define quality cost drivers in AM process chain and to put them in the flow chart to investigate the effect of each of them on others.

\section{Generic structure for AM quality system}

After applying the basic quality control management system to the generic process chain and implementing the P-A-F model, activities as maintenance, inspection and process control, and failure replacements appeared in the flow chart as shown in Figure 2 below: 


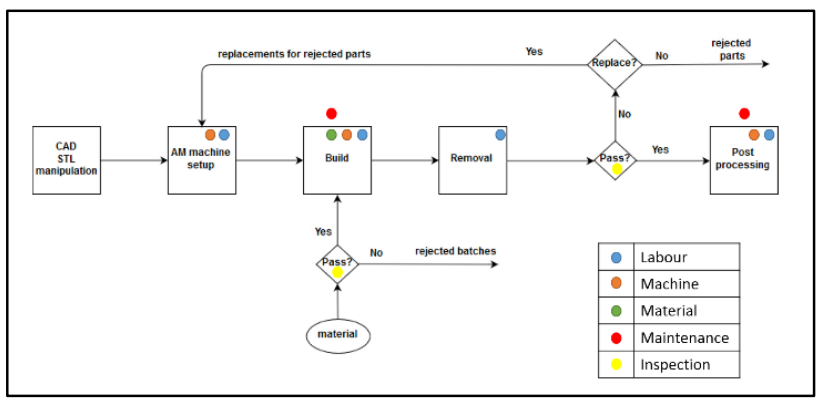

Figure 2: Quality activities in AM process chain

Figure 2 shows that there are five cost drivers regarding the quality control along the process chain. The most frequent are labour cost which starts to appear from setup and continues through build and removal process, and however, it may also exist in the finishing and post processing steps if the finishing was manual. The material is only consumed to manufacture the parts, so its cost is less frequent and only incurred during the build step, whereas machines consume energy in three stages; setup, build and post processing. All those costs are associated with manufactured parts and consequently the replacements.

Raw material needs to be inspected before it enters the AM machine for the build process, therefore, if it did not match the required properties it will be rejected. This inspection process lessens the probability of losses in the building process. Another inspection point is needed after the parts are built so that defects do not go on to the post processing step, therefore no additional cost incurred there. In case of batch production, besides the inspection cost, a process control station will be more favoured.

The third part of the cost rises from preventive maintenance for both AM machine and post processing machine. Preventive maintenance cost is usually an annual cost paid to maintain the machines in good and stable condition all over the year.

All of those costs can be sorted and organised in P-A-F chart as shown in Figure 3. Preventive maintenance is laid down the prevention branch of quality cost, where inspection is part of the appraisal actions of quality control. Failure cost is represented by replacements cost which consists of materials, machine, labour and overheads costs.

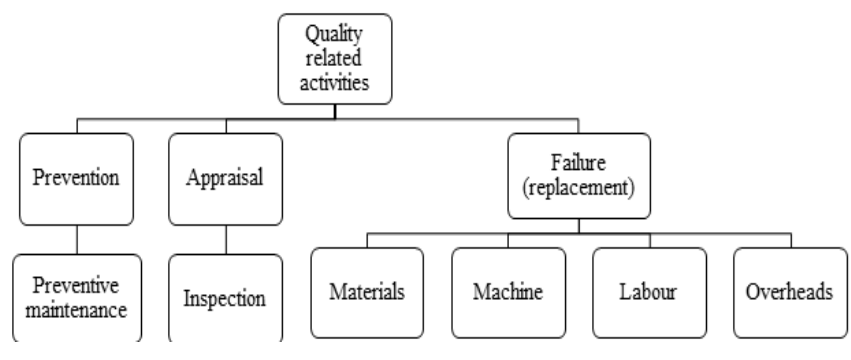

Figure 3: P-A-F quality cost model

[14] in their model, summed up the machine, labour and overheads cost as indirect cost, where material cost is presented as a direct cost. The same concept is applied for the replacements. Thus they are presented in the same categories in the new cost model.

\section{Proposed quality cost model for AM}

Cost of quality that is discussed in [22] model includes the cost of preventive maintenance, material inspection and testing, process control, final inspection, and post-processing cost. Those costs are grouped as visible quality cost [24]. To consider all aspects of quality cost, researchers in [24] added another group listed as invisible quality cost. This group mainly associated with the cost of failure and defective parts. It contains the additional cost of material, machine, and labours caused by building replacements for defective parts. However, cost of replacements can be treated as same as original part in unit cost basis and thus build cost from [14] could be used. So, the total cost of quality can be expressed as follow:

\section{Material cost}

Material cost is the cost associated with the material used during the building process. Amount of required material differs from one AM technology to another. However, they are directly related to masses of manufactured parts and their quantities. Material cost is the multiple of material unit cost times the total amount of material used during the manufacturing process, Error! Reference source not found..

$C_{m}=\sum_{i=1}^{I} C M T(i) \times m(i) \times n(i)$

\section{Indirect cost}

Labour and machine costs, which could be considered as direct costs, were assigned indirectly, this is because they are paid yearly as per fixed contracts. Indirect cost is related to the time of building. Hence the total indirect cost is the sum of indirect cost rate times the building time, Error! Reference source not found.. 
$C_{\text {indirect }}=\sum_{i=1}^{I} \dot{C}_{\text {indirect }} \times t_{B}(i)$

\section{Replacements cost}

The summation of material and indirect cost is total production cost, however, replaced parts are considered as a percentage of the total planned number of the parts. So, the replacements cost equals the production cost times the percentage of defects, Error! Reference source not found..

$$
C_{r}=\left(C_{\text {indirect }}+C_{m}\right) * P_{\text {reject }}
$$

\section{Scrap revenue}

The profit from scrap selling is calculated as same as material cost, however the unit price for scraps much lower than material unit cost, Error! Reference source not found..

$C_{s c}=\sum_{i=1}^{I} P R C(i) \times m(i) \times n_{r}(i)$

\section{Inspection cost}

Inspection cost is the cost of examining the conformance of the product during its several stages of manufacturing. The Inspection process would be extremely critical, and the passing of any defectives would result in an unacceptably high failure cost at subsequent stages, in this case, a full inspection is more appropriate. Otherwise, acceptance sampling may be used, this provides the less expensive option but has risks of tolerating bad lots and discarding good lots. The inspection cost is directly related to some parts to be inspected. Thus total inspection cost equals cost for inspecting one part times the total number of inspected parts, Error! Reference source not found.

$C_{\text {in }}=\sum_{i=1}^{I} \operatorname{Cis} * n(i)$

Preventive maintenance cost

Preventive maintenance is essential to keep machines operating in advance of their failure. Maintenance cost is usually an annual cost that is paid every year for each machine by contracts. Therefore, the total annual preventive maintenance cost is the summation of preventive maintenance cost for each machine, Error! Reference source not found.

$$
C_{p m}=\sum_{j=1}^{J} P M C(j)
$$

Where:

$\dot{C}_{\text {indirect }}=$ indirect cost rate $[£ / \mathrm{h}]$
$\mathrm{t}_{\mathrm{B}}(\mathrm{i})=$ total build time of part $\mathrm{i}[\mathrm{h}]$

CMT (i) = cost per unit of material $[£ / \mathrm{kg}]$

$\mathrm{m}(\mathrm{i})=$ mass of part (i) $[\mathrm{kg}]$

$\mathrm{n}(\mathrm{i})=$ number of parts (i)

PRC $(\mathrm{i})=$ price of scrapped parts $[£ / \mathrm{kg}]$

$\mathrm{n}_{\mathrm{r}}(\mathrm{i})=$ total number of defect parts (i)

$\mathrm{PMC}=$ preventive maintenance cost per year of machine $\mathrm{j}$ [£/annum]

Cis= inspection unit cost $[£ /$ part $]$

$p_{\text {reject }}(i)=$ probability of rejection for part (i)

\section{Total quality cost (TQC)}

Quality cost rises from all quality related activities, so it includes the cost of making replacements for defect parts as well as failure cost, it also includes the cost of inspecting the parts after they leave the build machine. The cost of maintaining the machine in good conditions is also part of the quality cost. Despite those costs, sometimes failures may generate profits if they are sold as scrap. However, it is better to not having them at all by keeping the quality of manufacturing as high as possible. Therefore, the total quality cost is the summation of replacements, inspection, and preventive maintenance cost, and the scrap profit is subtracted from this cost, Error! Reference source not found..

$$
\begin{aligned}
T Q C=C_{r}-C_{s c}+C_{\text {in }} & +C_{p m} \\
T Q C=\sum_{i=1}^{I} \dot{C}_{\text {indirect }} \times t_{B r}(i) & \\
& +\sum_{i=1}^{I} \operatorname{CMT}(i) \times m(i) \times n_{r}(i) \\
& -\sum_{i=1}^{I} \operatorname{PRC}(i) \times m(i) \times n_{r}(i) \\
& +\sum_{i=1}^{I} \operatorname{Cis} * n(i) \\
& +\sum_{j=1}^{J} \operatorname{PMC}(j)
\end{aligned}
$$

\section{Total manufacturing cost (TMC)}

Total manufacturing cost is the money that is spent during manufacturing combination of parts through AM machine, and it equals actual 
production cost plus quality cost. Production cost used in this model is the same as in [13] model, where quality cost as discussed above, Error! Reference source not found..

$\mathrm{TMC}=C_{\text {indirect }}+C_{m}+C_{r}-$

$C_{s c}+C_{i n} C_{p m}$

\section{Unit cost}

Unit cost is the amount of total cost to produce a product divided by its quantity. It can be used to assess a company's production efficiency. The unit cost to produce (n) parts of the same type can be mathematically expressed as shown in Error! Reference source not found.

$$
\operatorname{Cost}_{p}(i)=\frac{T M C}{n}
$$

In some cases, where more than one type of product is made simultaneously in one building process, then certain techniques are used to calculate unit cost. One of those techniques is by using volume fraction of the part. The volume fraction is the volume of one part divided by the total volume of the build. Therefore, unit cost will be total manufacturing cost times volume fraction of part (i), Error! Reference source not found.

$\operatorname{Cost}_{p}(i)=T M C * \frac{V_{p}(i)}{V_{B}}$

\section{Scenarios of failures}

There are three scenarios for the failures of manufactured parts. The first case is when the quality level is quite high, and there are no failures happen during the manufacturing process, so in this case, no additional cost is incurred, and the number of parts remains the same as planned. This case could be used as a base line for the two other scenarios. Unit cost for this case can be calculated using Error! Reference source not found.

$$
\begin{array}{r}
\operatorname{Cost}_{p}(i)=\frac{T M C}{n} \\
\mathrm{TMC}=C_{\text {indirect }}+C_{m}+C_{i n}+C_{p m}
\end{array}
$$

In the second case, some failures happen, and consequently, some parts are rejected since they are described as defects and cannot be used, again the total manufacturing cost will remain the same as in the first case since there are no replacements made to compensate the rejected parts. The number of useful parts will not be the same because of rejected parts. Accordingly, the unit cost for this case will increase since the total manufacturing cost is divided by less number of parts, Error! Reference source not found. .

$$
\begin{array}{r}
\operatorname{Cost}_{p}(i)=\frac{T M C}{\left(n-n_{r}\right)} \\
\mathrm{TMC}=C_{\text {indirect }}+C_{m}-C_{s c}+C_{\text {in }}+ \\
C_{p m}
\end{array}
$$

The third case is almost the same as the second. However, the rejected parts are compensated by manufacturing some replacements. Thus total manufacturing cost increase by the cost of replacements, where the number of useful parts becomes again as planned, Error! Reference source not found..

$$
\begin{gathered}
\operatorname{Cost}_{p}(i)=\frac{T M C}{n} \\
\mathrm{TMC}=C_{\text {indirect }}+C_{m}+C_{r}-C_{s c}+C_{\text {in }}+C_{p m}
\end{gathered}
$$

\section{Case study}

The manufacturing cost of the same part (lever) introduced by [14]. Figure 4, was estimated using the developed cost model. They presented a full machine bed envelope, which contained 896 parts, with a volume of $7106 \mathrm{~mm}^{3}$ each. Table1 shows the details about part manufacturing quantities, material, and related quality costs.

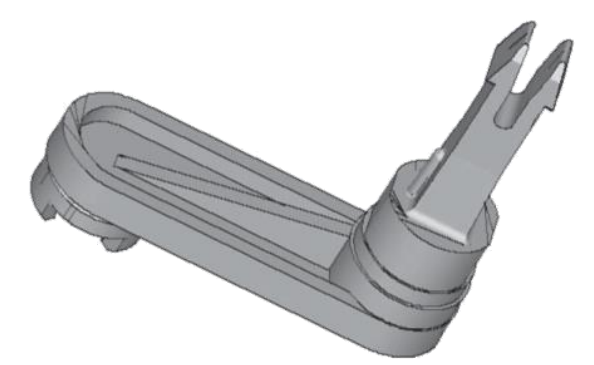

Figure 4: Lever, the object of the study

In this research study [14], the model maintenance and post processing costs are included in the indirect cost. When applying the new cost model to calculate total manufacturing cost and quality cost to produce 16000 unit of the lever in a year, the results came out as shown in Figure 5Figure 6, Figure 6.

Table1: The lever manufacturing characteristics

\begin{tabular}{|l|l|l|}
\hline Model & Ruffo et al. & Schmid and Levy \\
\hline $\begin{array}{l}\text { AM } \\
\text { technology }\end{array}$ & SLS & SLS \\
\hline Material & $\begin{array}{l}\text { Duraform } \\
\text { PA }\end{array}$ & Plastic powder \\
\hline
\end{tabular}


International Journal of Engineering Applied Sciences and Technology, 2020

Vol. 5, Issue 1, ISSN No. 2455-2143, Pages 124-133

Published Online May 2020 in IJEAST (http://www.ijeast.com)

\begin{tabular}{|c|c|c|}
\hline $\begin{array}{l}\text { Annual } \\
\text { production } \\
\text { (parts) }\end{array}$ & 16000 & 2000 \\
\hline $\begin{array}{l}\text { Working hours } \\
\text { (h/year) }\end{array}$ & 5000 & - \\
\hline Utilization & $50 \%$ & $50 \%$ \\
\hline $\begin{array}{l}\text { Depreciation } \\
\text { time (years) }\end{array}$ & 8 & 10 \\
\hline Part price $(€)$ & 3.25 & 200 \\
\hline $\begin{array}{l}\text { Quality } \\
\text { considerations }\end{array}$ & $\begin{array}{l}\text { maintenance } \\
\text { post } \\
\text { processing }\end{array}$ & $\begin{array}{l}\text { equipment fitness } \\
\text { and maintenance } \\
\text { material inspection } \\
\text { process control } \\
\text { part finishing }\end{array}$ \\
\hline $\begin{array}{ll}\text { Material } & \text { unit } \\
\text { cost }(€ / \mathrm{kg}) & \end{array}$ & 58 & - \\
\hline $\begin{array}{ll}\text { Indirect } & \text { cost } \\
\text { rate }(€ / h) & \end{array}$ & 29.08 & - \\
\hline $\begin{array}{l}\text { Inspection unit } \\
\text { cost }(€ / \text { part })\end{array}$ & - & 5 \\
\hline $\begin{array}{l}\text { Post } \\
\text { processing cost } \\
(€ / \text { part })\end{array}$ & - $\quad *$ & 25 \\
\hline $\begin{array}{l}\text { Maintenance } \\
\text { cost (€/year) }\end{array}$ & $21750 *$ & 35000 \\
\hline $\begin{array}{ll}\text { Part } & \text { volume } \\
(\mathrm{mm} 3) & \end{array}$ & 7106 & - \\
\hline $\begin{array}{l}\text { Density } \\
(\mathrm{g} / \mathrm{cm} 3)\end{array}$ & 0.6 & - \\
\hline $\begin{array}{l}\text { Probability of } \\
\text { part rejection }\end{array}$ & \multicolumn{2}{|l|}{0.07 as in [29] } \\
\hline
\end{tabular}

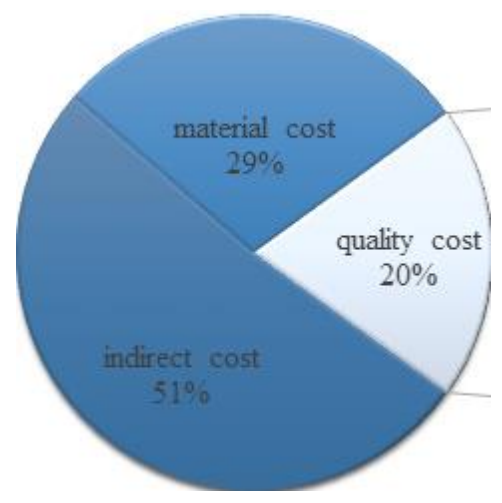

Figure 5: Total manufacturing cost

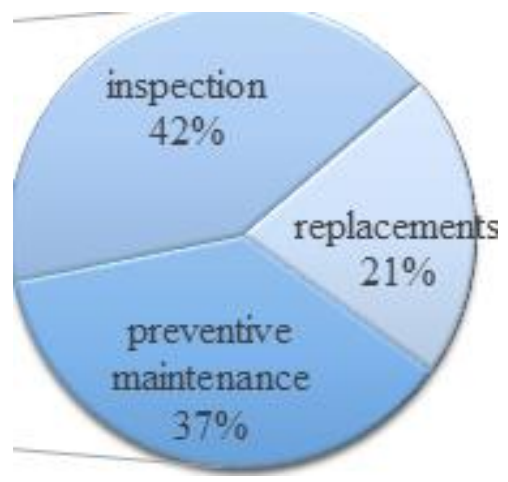

Figure 6: Quality cost

Half of manufacturing cost was due to the indirect cost which includes production labour cost, machine purchasing cost, and other overhead costs. Material cost represents almost one-third of total manufacturing cost, this fact due to the light weight of manufactured part and its relatively small quantity (3.2 part/hour). The ratio between material and indirect cost is almost the same as in [14] model. However, Ruffo et al. [14] did not consider quality cost, which it turned to represent $20 \%$ of total manufacturing cost in the new model.

Preventive maintenance cost was found to represent about two-fifths of quality cost nearly the same as inspection cost, whereas the least percentage reflected the replacements cost.

By dividing total manufacturing cost in a year by 16000 units of the lever, unit cost was found about $3.7 €$, which is higher than [13] unit cost by 0.45 $€ /$ part.

\section{DISCUSSION}

Among the cost models found in literature, [22] model was the first model that discussed quality cost for AM in details, meanwhile [14] model was the one in which detailed figures about part manufacturing cost were found, and at the same time it was considering some quality issues such as maintenance cost and post processing cost. For 
this reason, a comparison in total manufacturing cost and unit cost was made between them.

As shown in Figure 7, the quality cost in [14] model only represented less than $10 \%$ of total manufacturing cost, and it doubled in [22] model, however, in the new model it was $20 \%$ of total manufacturing cost. [14] Only considered maintenance and post proceeding cost as quality cost, where in [22] model, inspection and process control were added to the quality cost. Replacements cost which is known as failure cost was not considered in any of past quality cost models, though $[29,30]$ in their report added some cost to labour cost due to building or part failure as if it was a loss from their production time.

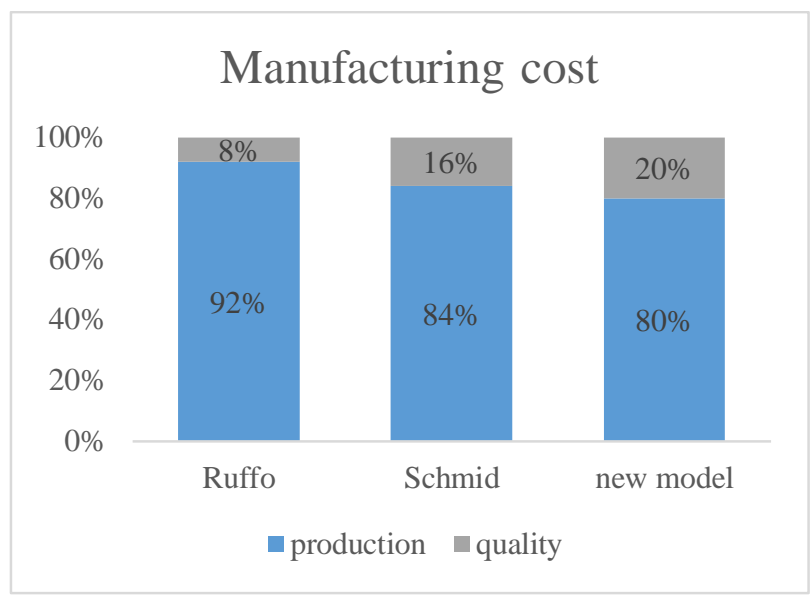

Figure 7: Total manufacturing cost using three cost models

When the unit cost calculated for the lever using the new cost model it found in [14] did not consider about $€ 0.45$ per part which is considerable amount when the production of 16000 parts was taken into account, and the difference was $€ 7,500$ per year. Especially when the total manufacturing cost was about $€ 60,000$ per year. The cause of this difference was the inspection and replacements cost, which was introduced in the new cost model, as shown in Figure 8.

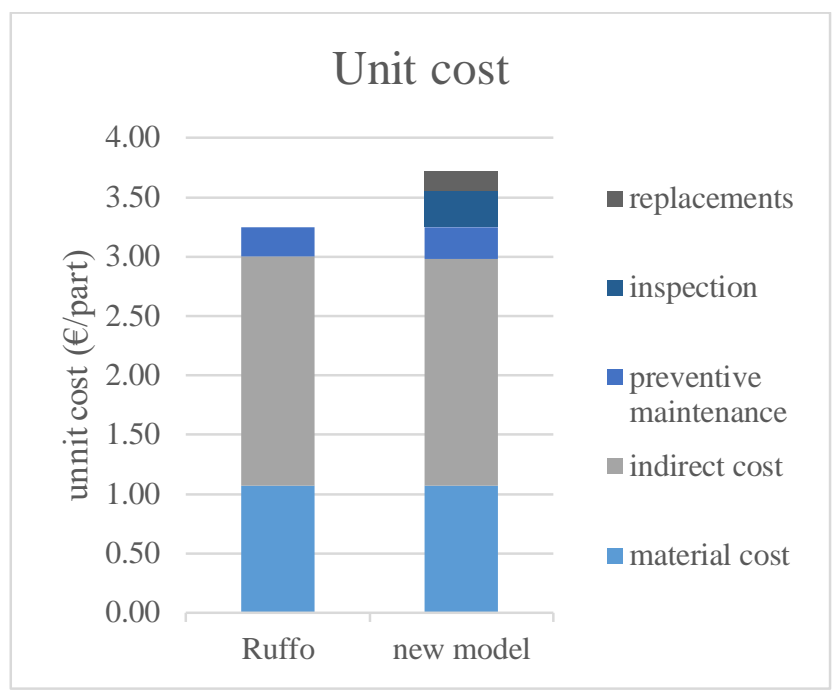

Figure 8: Comparison between unit cost of Ruffo et al.

Considering the three scenarios regarding the failure of manufactured parts, the unit cost was calculated in each case, and Figure 9 shows that the best scenario was the first case at which there were no any rejected parts. This is because there was no additional cost of replacements. In the second case, unit cost was higher than the first case because of replacements cost. Unexpectedly, the unit cost in the third was further higher than the second case even though there were no replacements for rejected parts. This increase in unit cost was because the total manufacturing cost was divided by a smaller number of parts since the rejected parts were not useful anymore.

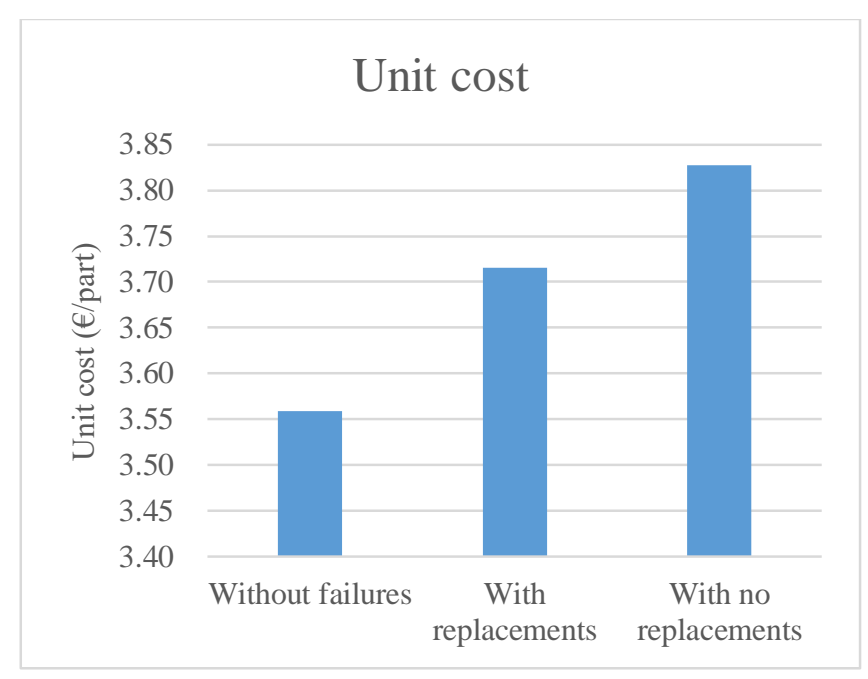

Figure 9: Three scenarios of failures

Further investigation on the effect of replacements on unit cost was carried out, and the results were found as presented in Figure 10. It found that for a high percentage of defects in the batch the gap between the unit cost for the second and third 
scenarios became bigger, and thus it is always better to have replacements for the rejected parts.

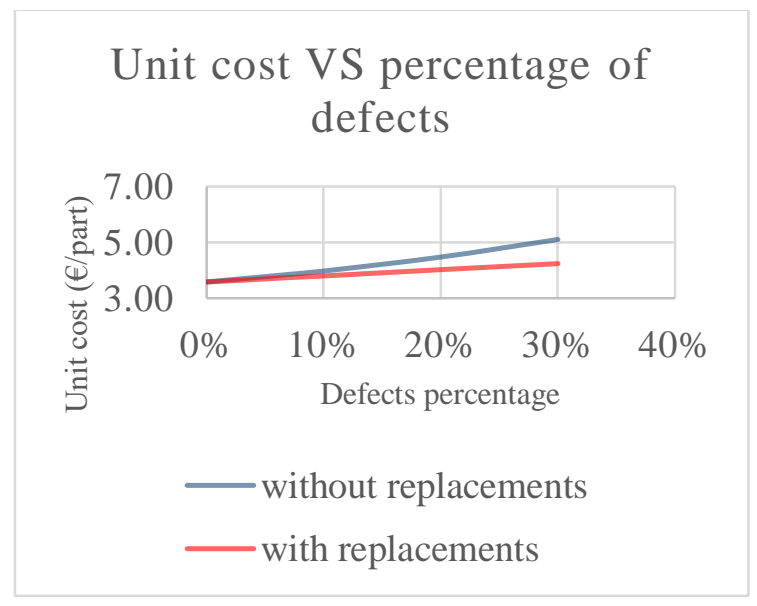

Figure 10: Effect of defects percentage on unit cost

\section{CONCLUSIONS}

Ruffo et al. [14] model was the main method used to estimate the cost of parts made through LS technology since 2006. However, it was inaccurate regarding quality cost. In this study, new cost model was presented, this model was based on a 'full costing' concept that includes direct, indirect, preventive maintenance, inspection, and replacements cost. All quality activities defined in AM process chain are shown in Figure 2.

The developed cost model, with quality aspects, was used to calculate the manufacturing cost of a lever; it found that $20 \%$ of manufacturing cost is originated from quality cost. Ruffo et at. [14] model found the quality cost only about $8 \%$ considering only maintenance cost. Inspection cost was considered in [22] model in addition to maintenance cost, that is why the quality cost rose to about $16 \%$ of the total manufacturing cost. None of those two models was considering the replacements cost, which was found to be about $4 \%$ of the total manufacturing cost, as per the developed cost model.

Three scenarios regarding the failure of parts after the building process were investigated. In the first scenario, where all built parts were accepted, and no defects were found, the unit cost was found to be $€ 3.55 /$ part. While in the second scenario, where for each rejected parts a replacement was made, the total manufacturing cost increased, leading to a unit cost of $€ 3.71 /$ part. Finally, in the third scenario, where parts defected were rejected without being replaced, the unit cost was found to be $€ 3.82 /$ part, even though the manufacturing cost was the same as the first scenario. However, the number of useful parts was less than the planned number. Thus the total manufacturing cost was distributed over a smaller number of parts, and that was the cause of the increase in unit cost.

The effect of percentage of parts defected on the unit cost was also studied, it was found that higher percentage of defects was associated with higher unit cost. This effect was even higher when no replacements were made for defected parts. The study showed that for a higher percentage of defects it is always better to have replacements for the rejected parts.

\section{REFERENCES}

[1] ASTM 2012. ASTM F2792-12a, Standard Terminology for Additive Manufacturing Technologies.

[2] Sampath, S., and Herman, H. (1993). Plasma spray forming metals, intermetallics, and composites. JOM, 45(7), 42-49.

[3] Elamin, M., Li, B., and Tan, K. T. (2018). Impact damage of composite sandwich structures in arctic condition. Composite Structures, 192, 422-433.

[4] Khan, M. H., Elamin, M., Li, B., and Tan, K. T. (2018). X-ray micro-computed tomography analysis of impact damage morphology in composite sandwich structures due to cold temperature arctic condition. Journal of Composite Materials, 52(25), 3509-3522.

[5] TAN, K., ELAMIN, M., and LI, B. (2017). Impact Performance and Damage Behavior of Composite Sandwich Structures in Arctic Condition. In Proceedings of the American Society for Composites-Thirty-second Technical Conference.

[6] Elamin, M., Li, B., and Tan, K. T. (2018). Impact Performance of Stitched and Unstitched Composites in Extreme Low Temperature Arctic Conditions. Journal of Dynamic Behavior of Materials, 4(3), 317-327.

[7] Elamin, M., and Varga, J. (2020). Plate impact method for shock physics testing. Material Sci \& Eng, 4(1), 31-35.

[8] GIBSON, I., ROSEN, D. W. and STUCKER, B. (2010). Additive manufacturing technologies, Springer.

[9] ROMBOUTS, M., KRUTH, J. P., FROYEN, L. and MERCELIS, P. (2006). Fundamentals of Selective Laser Melting of alloyed steel powders. CIRP Annals Manufacturing Technology, 55, 187-192. 
[10] RICKENBACHER, L., SPIERINGS, A. and WEGENER, K. (2013). An integrated cost-model for selective laser melting (SLM). Rapid Prototyping Journal, 19, 208-214.

[11] HAGUE, R., CAMPBELL, I. and DICKENS, P. (2003). Implications on design of rapid manufacturing. Proceedings of the Institution of Mechanical Engineers, Part C: Journal of Mechanical Engineering Science, 217, 25-30.

[12] TUCK, C. J., HAGUE, R. J., RUFFO, M., RANSLEY, M. and ADAMS, P. (2008). Rapid manufacturing facilitated customization. International Journal of Computer Integrated Manufacturing, 21, 245258.

[13] RUFFO, M. and HAGUE, R. (2007). Cost estimation for rapid manufacturing ' simultaneous production of mixed components using laser sintering. Proceedings of the Institution of Mechanical Engineers, Part B: Journal of Engineering Manufacture, 221, 15851591.

[14] RUFFO, M., TUCK, C. and HAGUE, R. (2006). Cost estimation for rapid manufacturing - laser sintering production for low to medium volumes. Proceedings of the Institution of Mechanical Engineers, Part B: Journal of Engineering Manufacture, 220, 1417-1427.

[15] THOMAS, D. S. and GILBERT, S. W. (2014). Costs and cost effectiveness of additive manufacturing. NIST Special Publication, 1176, 12.

[16] WOHLERS, T. and GORNET, T. (2014). History of additive manufacturing. Wohlers Report, 24, 2014.

[17] KHAJAVI, S. H., PARTANEN, J. and HOLMSTRÖM, J. (2014). Additive manufacturing in the spare parts supply chain. Computers in Industry, 65, 50-63.

[18] Lindemann, C., Jahnke, U., Moi, M., and Koch, R. (2012, August). Analyzing product lifecycle costs for a better understanding of cost drivers in additive manufacturing. In 23th Annual International Solid Freeform Fabrication Symposium-An Additive Manufacturing Conference. Austin Texas USA 6th-8th August.

[19] NIAZI, A., DAI, J. S., BALABANI, S. and SENEVIRATNE, L. (2005). Product Cost Estimation: Technique Classification and Methodology Review. Journal of Manufacturing Science and Engineering, 128, 563-575.

[20] ALEXANDER, P., ALLEN, S. and DUTTA, D. (1998). Part orientation and build cost determination in layered manufacturing. Computer-Aided Design, 30, 343-356.
[21] HOPKINSON, N. and DICKNES, P. (2003). Analysis of rapid manufacturing - using layer manufacturing processes for production. Proceedings of the Institution of Mechanical Engineers, Part C: Journal of Mechanical Engineering Science, 217, 31-39.

[22] SCHMID, M. and LEVY, G. (2014). Quality management and estimation of quality costs for additive manufacturing with SLS, ETH-Zürich.

[23] JURAN, J. and GODFREY, A. B. (1999). Quality handbook. Republished McGraw-Hill.

[24] FEIGENBAUM, A. V. (1991). Total Quality Control, McGraw-Hill.

[25] CROSBY, P. B. (1979). Quality is free: the art of making quality certain, New York, McGraw-Hill.

[26] ROSS, D. T. (1977). Structured analysis (SA): A language for communicating ideas. IEEE Transactions on software engineering, 16-34.

[27] MARSH, J. (1989). Process modeling for quality improvement. 1989 1989. IFS Publications Bedford.

[28] CHIADAMRONG, N. (2003). The development of an economic quality cost model. Total cost perspective. The University of Nottingham.

Quality Management \& Business Excellence, 14, 9991014.

[29] BAUMERS, M., HOLWEG, M. and ROWLEY, J. (2015). The economics of 3D Printing: A total cost perspective. 3DP-RDM, University of Cambridge.

[30] Elamin, M., Li, B., and Tan, K. T. EFFECT OF LOW TEMPERATURE ON IMPACT BEHAVIOR OF COMPOSITE SANDWICH STRUCTURES. 